\title{
Cerebrospinal fluid promotes survival and astroglial differentiation of adult human neural progenitor cells but inhibits proliferation and neuronal differentiation
}

Judith Buddensiek', Alexander Dressel ${ }^{1}$, Michael Kowalski', Uwe Runge ${ }^{1}$, Henry Schroeder $^{2}$, Andreas Hermann $^{3}$, Matthias Kirsch ${ }^{4}$, Alexander Storch ${ }^{3}$, Michael Sabolek ${ }^{1 *}$

\begin{abstract}
Background: Neural stem cells (NSCs) are a promising source for cell replacement therapies for neurological diseases. Growing evidence suggests an important role of cerebrospinal fluid (CSF) not only on neuroectodermal cells during brain development but also on the survival, proliferation and fate specification of NSCs in the adult brain. Existing in vitro studies focused on embryonic cell lines and embryonic CSF. We therefore studied the effects of adult human leptomeningeal CSF on the behaviour of adult human NSCs (ahNSCs).

Results: Adult CSF increased the survival rate of adult human NSCs compared to standard serum free culture media during both stem cell maintenance and differentiation. The presence of CSF promoted differentiation of NSCs leading to a faster loss of their self-renewal capacity as it is measured by the proliferation markers Ki67 and $\mathrm{BrdU}$ and stronger cell extension outgrowth with longer and more cell extensions per cell. After differentiation in CSF, we found a larger number of GFAP ${ }^{+}$astroglial cells compared to differentiation in standard culture media and a lower number of $\beta$-tubulin $\mathrm{II}^{+}$neuronal cells.

Conclusions: Our data demonstrate that adult human leptomeningeal CSF creates a beneficial environment for the survival and differentiation of adult human NSCs. Adult CSF is in vitro a strong glial differentiation stimulus and leads to a rapid loss of stem cell potential.
\end{abstract}

\section{Background}

Neural stem cells (NSCs) are a promising source for cell replacement therapies in the brain and the spinal cord [1]. It is common knowledge that NSCs can be extracted from fetal brain [2-4] or generated from embryonic stem cells $[2,5-8]$. Furthermore, NSCs can also be isolated from different regions of the adult brain such as the hippocampus and the subventricular zone and from some non-neurogenic regions such as the spinal cord [2,3,9-13] or the periventricular regions of the whole neuroaxis [14]. NSCs are able to replicate and generate all neuroectodermal lineages, namely neurons, astroglia and oligodendroglia $[2,3,15]$. During in vitro expansion,

\footnotetext{
* Correspondence: michael.sabolek@uni-greifswald.de

* Correspondence: michael.sabolek@uni-greifswald.de
'Department of Neurology, Ernst Moritz Arndt University of Greifswald,

17475 Greifswald, Germany
}

NSCs grow in so-called "neurospheres" or adherent cultures. Neurospheres are either multicellular aggregates or clones originating from one single cell depending on the cell density $[3,9,11,15]$. In previous studies, the isolation and successful long-term expansion of human NSCs from the adult hippocampus, the adult olfactory bulb and adult post-mortem tissues have been reported [16-20]. In these studies, ahNSCs have successfully been expanded for more than 30 population doublings using serum-free culture medium which is normally supplemented with the mitogenes epidermal growth factor (EGF) and fibroblast growth factor 2 (FGF-2). Removal of the mitogenes leads to spontaneous differentiation of adult NSCs into neurons, astroglia and oligondendroglia [16-20].

Investigations examining the influence of CSF and its contents on survival, proliferation and differentiation of 
NSCs were so far mostly performed with embryonic avian CSF [21-23]. In these investigations, NSCs cultured in CSF showed an increased survival rate and a higher number of BrdU positive, DNA synthesizing nuclei, compared to standard culture media. In addition a larger number of beta-tubulin $\mathrm{III}^{+}$, immature neurons, has been detected compared to standard culture media, indicating a positive influence of embryonic avian CSF on neurogenesis. As there are well known differences between avian and mammalian CSF [24] with a much greater complexity of mammalian CSF, the transferability of these results to human conditions is not yet clear. Also, they might be a difference in between effects of adult CSF on NSCs and embryonic CSF effects. Still, this is not yet investigated, even though it has been suggested that CSF plays an important role not only during brain development but also for the survival, proliferation and differentiation of neuroectodermal stem cells in vivo [21-23,25-27]. In this present study we therefore used an in vitro cell system of adult human NSCs in culture as a model to investigate the effects of adult human CSF on NSC behaviour.

\section{Results}

\section{CSF increases the survival rate of adult human NSCs}

After in vitro expansion for at least three passages in standard media, NSCs were transferred to uncoated chamber slides and expanded in standard expansion medium or CSF for additional $72 \mathrm{~h}$. Thereafter, cells were stained with Hoechst 33342 and propidiumiodid to determine the amount of necrotic cells. Our results showed a significantly higher survival rate of NSCs in CSF compared to standard expansion medium (see Materials and Methods) with $6.9 \pm 1.9 \%$ of necrotic cells in CSF versus $46.0 \pm 12.9 \%$ in expansion medium $(P=$ 0.013; Fig. 1). Addition of the bone morphogenic protein (BMP) inhibitor Noggin did not significantly increase cell death rates compared to CSF without Noggin (5.2 \pm $2.4 \%$ of necrotic cells, $P=0.54$; Fig. 1 ). Similar results were obtained during in vitro differentiation with significantly higher survival rates in CSF compared to standard differentiation media: After $24 \mathrm{~h}$ in P4-8F media, $20.3 \pm 2.6 \%$ of NSCs were found necrotic versus $10.1 \pm$ $2.9 \%$ in CSF $(P=0.021)$. After $72 \mathrm{~h}$, the proportion was $22.7 \pm 7.5 \%$ versus $6.5 \pm 0.8 \%$ for standard media versus CSF, respectively $(P=0.038$; Fig. 2$)$. Again, addition of Noggin to CSF had no significant influence on the cell death rate during differentiation for the first $24 \mathrm{~h}(2.4 \pm$ $1.5 \%$ of necrotic cells, $P=0.09$ when compared CSF with CSF plus Noggin condition; Fig. 2).

\section{CSF inhibits proliferation of adult human NSCs}

To determine the influence of adult human leptomeningeal CSF on self-renewal potential of adult NSCs, we used the proliferation markers Ki67 and BrdU as readouts. For this, after in vitro expansion of at least three passages, cells were transferred to uncoated chamber slides and expanded in culture medium or CSF. The self renewing potential was determined at $24 \mathrm{~h}$ (Ki67) and $72 \mathrm{~h}$ (BrdU) after media was changed. At each time point, the percentage of $\mathrm{Ki} 7^{+}$and $\mathrm{BrdU}^{+}$NSCs was significantly higher in expansion medium compared to the one in CSF, representing a larger number of proliferating cells in expansion media. Hence, after 24 h Ki67 was detected in $20.4 \pm 7.3 \%$ of NSCs expanded in standard medium compared to only $0.2 \pm 0.01 \%$ of NSCs expanded in CSF $(P=<0.001$; Fig. 3$)$. For BrdU, we detected $42.8 \pm 15.7 \mathrm{BrdU}^{+}$cells $/ \mathrm{cm}^{2}$ in KO-DMEM, but only $2.4 \pm 2.8 \mathrm{BrdU}^{+}$cells $/ \mathrm{cm}^{2}$ in CSF $(P=0.023$, Fig. 3).

\section{CSF increases extension outgrowth velocity from adult human NSCs}

We used the time course of extension outgrowth as a first measure of the differentiation process of NSCs in culture. Thus, following expansion for at least three passages in vitro NSCs were allowed to differentiate. Cells were plated onto PLL-coated chamber slides in either differentiation media or CSF. For investigating extension outgrowth, number and length of extensions were determined at $0,3,6,24$ and $72 \mathrm{~h}$ after starting the differentiation process. Comparing results in $\mathrm{P} 4-8 \mathrm{~F}$ and CSF, we found significantly longer and a significantly more cell extensions per cell in CSF. After 24 and $72 \mathrm{~h}$ the difference was significant as NSC neurites getting twice as long in CSF (mean length: $14.5 \pm 2.6$ and $33.2 \pm 1.4 \mu \mathrm{m}$ after 24 and $72 \mathrm{~h}$, respectively) as in P4-8F (mean length: $7.7 \pm 0.9$ and $10.6 \pm 3.2 ; P=0.024[24 \mathrm{~h}]$ and 0.001 [72 h]; Fig. 4). Significant more cell extensions were determined in CSF for the time points $6 \mathrm{~h}, 24 \mathrm{~h}$ and $72 \mathrm{~h}$ with an average number of $1.3 \pm 0.0$ cell extensions in CSF after $6 \mathrm{~h}$ compared to $1.2 \pm 0.1$ neuritis in P4-8F. After $24 \mathrm{~h}$, the mean number of cell extensions was $1.5 \pm 0.1$ in CSF versus $1.2 \pm 0.1$ in P48F and after 72 hours cells had at an average of $2.0 \pm 0.1$ cell extensions in CSF compared to $1.5 \pm 0.1$ in $\mathrm{P} 4-8 \mathrm{~F}$ respectively. $(P=0.001,0.008$ and 0.005 , respectively; Fig. 4).

\section{CSF facilitates astrogliogenesis but inhibits neurogenesis from adult human NSCs}

To investigate the question whether the presence of adult human leptomeningeal CSF does have an influence on astrogliogenesis, oligodendrogenesis or neurogenesis, adult NSCs were allowed to differentiate for 7 days on PLL-coated chamber slides in either standard differentiation media or CSF. After differentiation in standard media, $24.7 \pm 1.7 \%$ of the cells were $\mathrm{GFAP}^{+}$, in contrast 

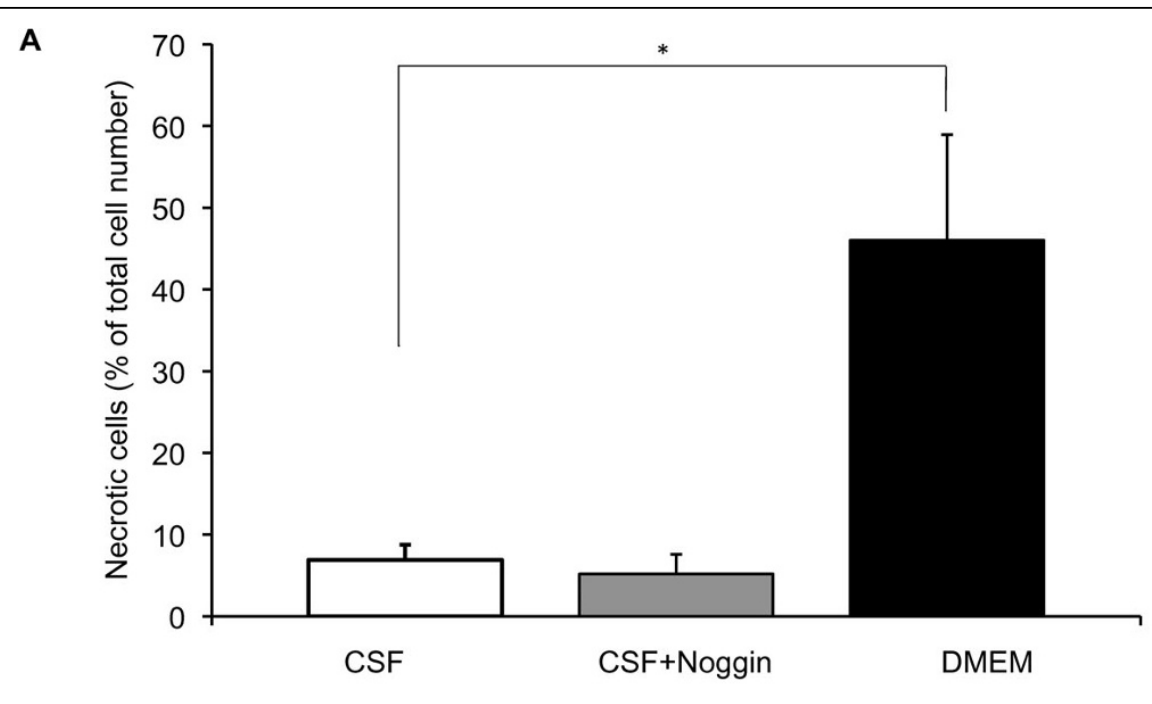

B

$\mathrm{PI} / \mathrm{HOECHST}$
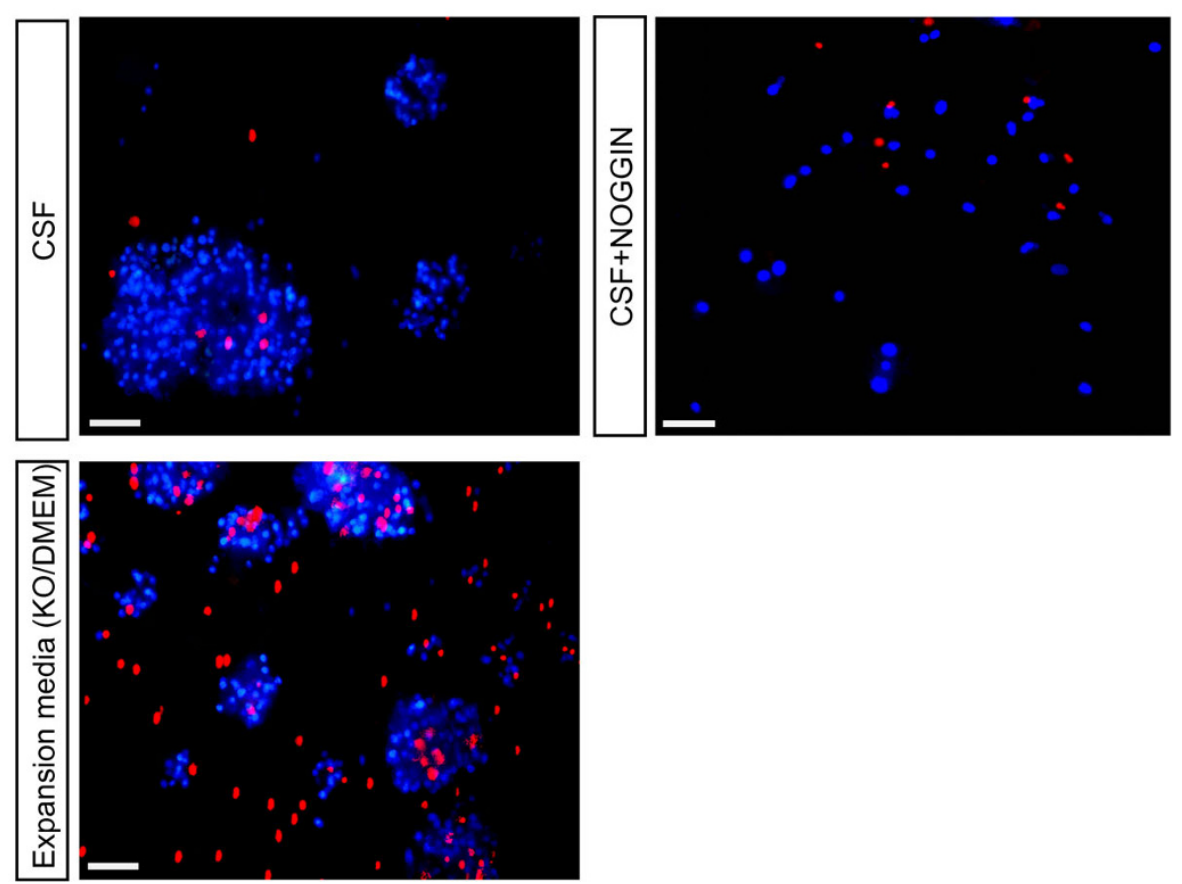

Figure 1 Survival rate of human adult NSCs during expansion. A, The percentage of necrotic NSCs expanded in culture medium supplemented with EGF and FGF-2 in comparison to CSF with or without $150 \mathrm{ng} / \mathrm{ml}$ Noggin was determined 72 hours after starting the expansion process. Values represent the mean \pm S.E.M from at least three independent experiments. ${ }^{*}$ indicates $P<0.05$ and ${ }^{* *} P<0.01$ compared to each corresponding value in CSF. B, Representative microphotographs demonstrating the influence of CSF on survival rate of NSCS. For immunostainings, dead cells were stained with propidiumiodid. Nuclei were counterstained with Hoechst 33342 . The upper panel shows NSCs expanded in CSF (left photograph) and CSF+Noggin (right photograph), the lower panel shows NSCs expanded in expansion media supplemented with EGF and FGF. Scale bar $=50 \mu \mathrm{m}$.

to $37.8 \pm 7.8 \mathrm{GFAP}^{+}$cells in CSF $(P=0.014$; Fig. 5$)$. The values for $\mathrm{GalC}^{+}$oligodendroglial cells and $\mathrm{MAP2}^{+}$neurons were $8.2 \pm 2.6 \% \mathrm{GalC}^{+}$and $0.2 \pm 1.7 \mathrm{MAP}^{+}$cells in standard media and $7.0 \pm 1.5 \mathrm{GalC}^{+}$and $0.4 \pm 0.6$ $\mathrm{MAP}^{+}$cells in CSF $(P>0.05)$. The low percentage of $\mathrm{MAP}^{+}$cells in standard media and CSF is most likely caused by the lack of fully differentiated phenotypes, as MAP2 represents a marker for mature neurons. Staining against the neuronal marker protein $\beta$-tubulin III, a marker for immature neurons, revealed $8.7 \pm 3.6 \% \beta$ tubulin $\mathrm{III}^{+}$cells in CSF compared to $30.7 \pm 8.4 \beta$-tubulin $\mathrm{III}^{+}$cells in standard media $(P=0.014)$. 
A

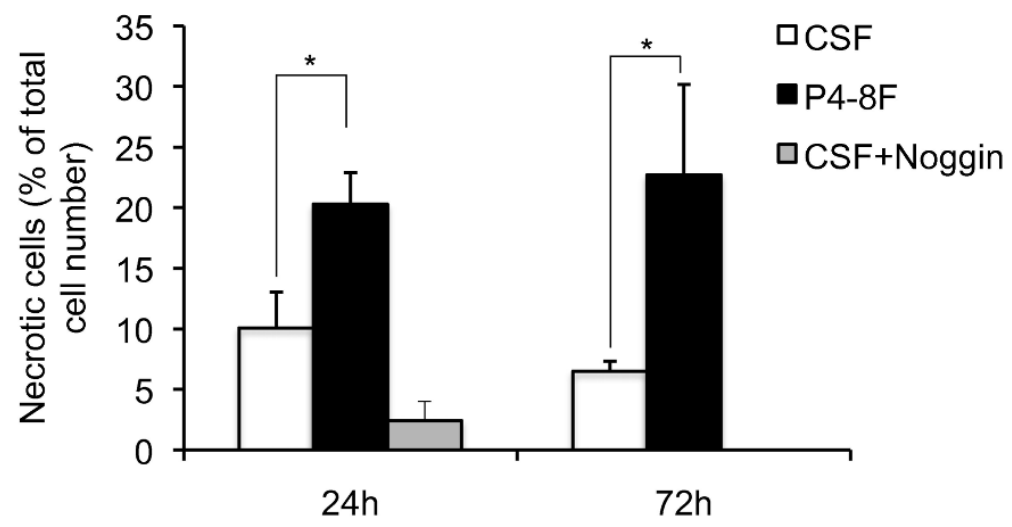

B
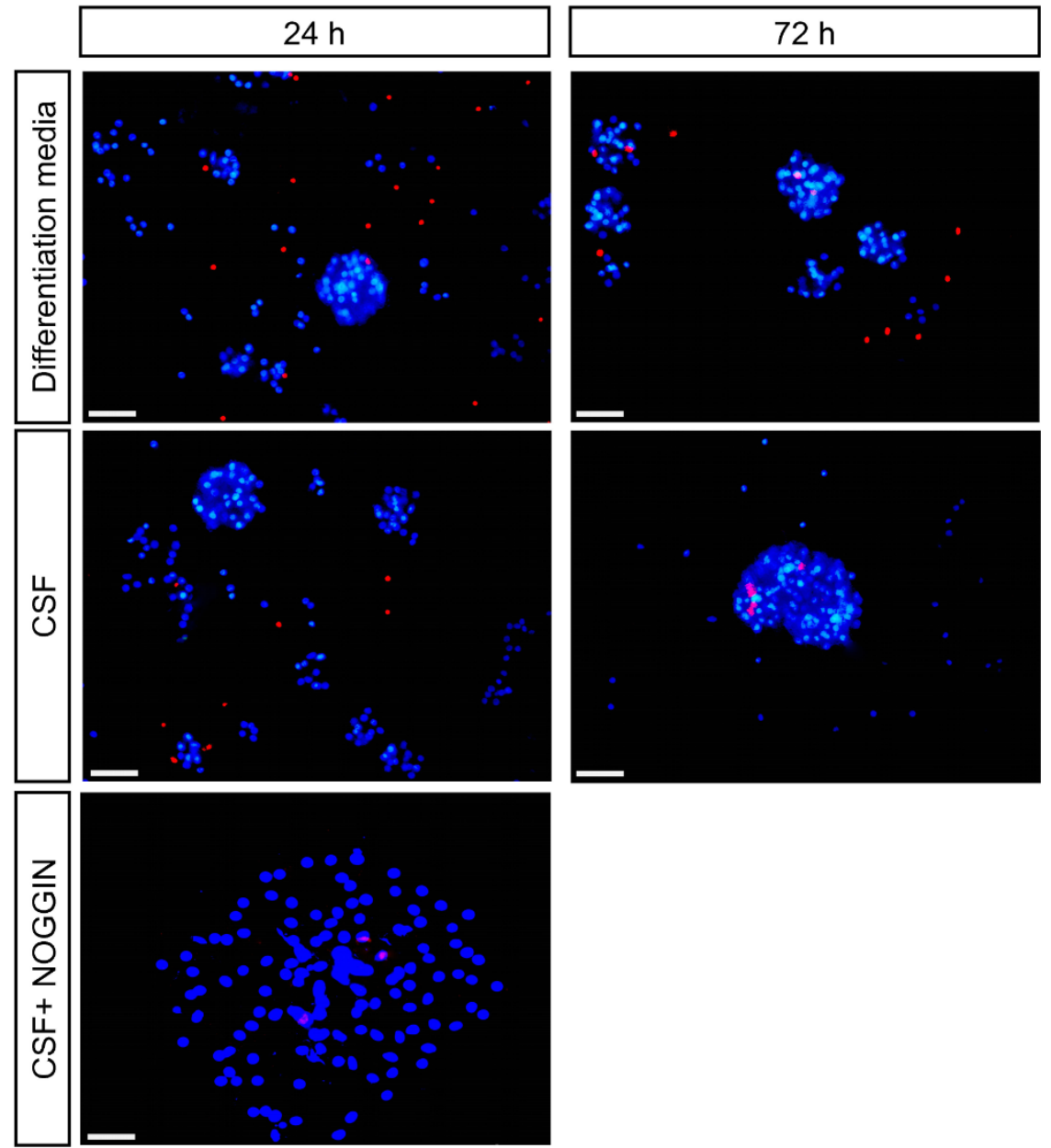

Figure 2 Survival rate of adult human NSCs during proliferation. A, The percentage of necrotic NSCs was determined at 24 and 72 hours after differentiation on PLL-coated chamber slides in P4-8F or CSF with or without $150 \mathrm{ng} / \mathrm{ml}$ Noggin. Values represent the mean \pm S.E.M from at least three independent experiments. ${ }^{*}$ indicates $P<0.05$ and ${ }^{* *} P<0.01$ compared to each corresponding value in CSF. B, Representative microphotographs demonstrating the influence of CSF on the survival rate of NSCs. For immunostainings, dead cells were stained with

propidiumiodid. Nuclei were counterstained with Hoechst 33342. The upper panel shows NSCs differentiated in differentiation media P4-8F, the middle panel shows NSCs differentiated in CSF, and the lower panel shows NSCs differentiated in CSF+Noggin. Scale bar $=50 \mu \mathrm{m}$. 


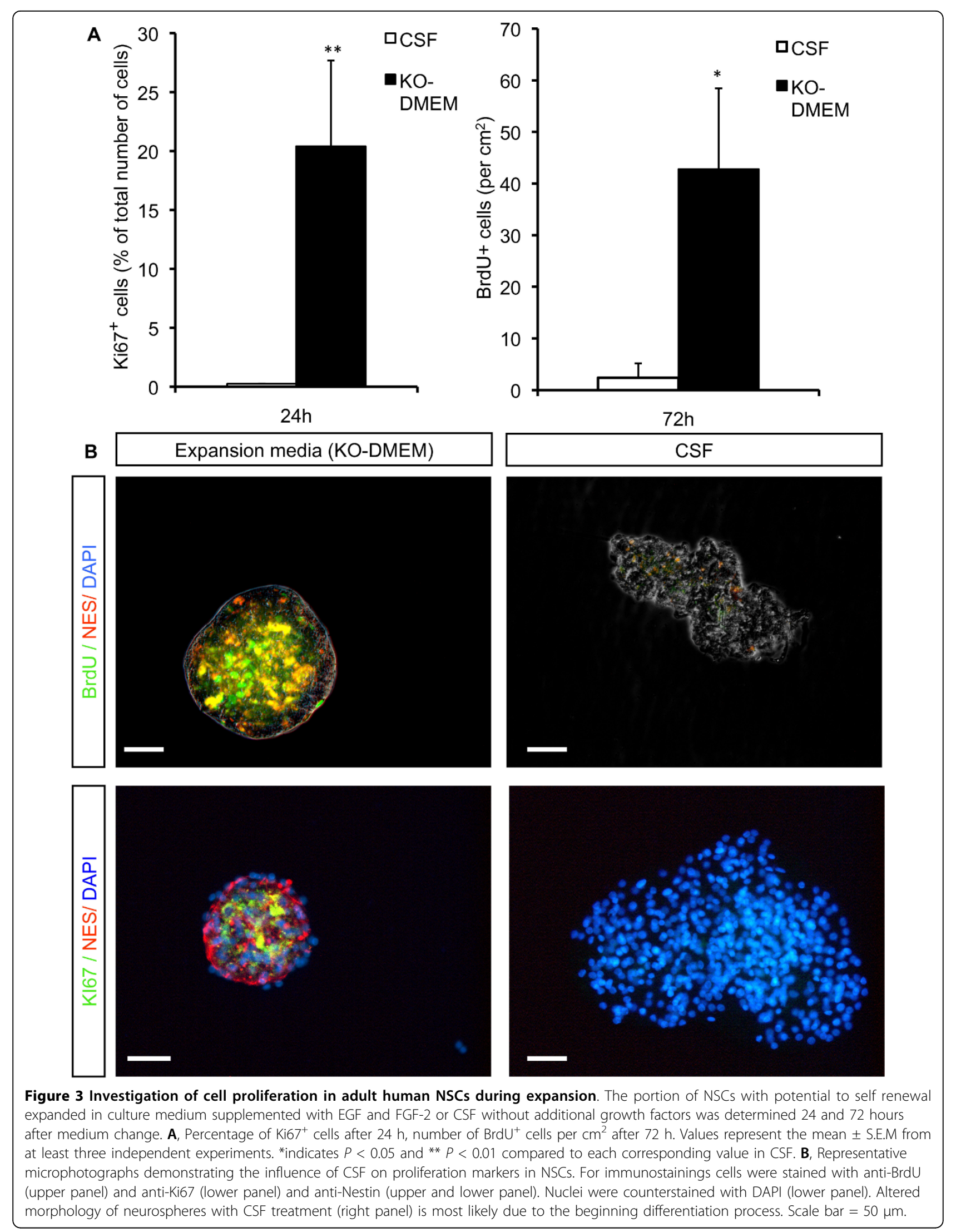




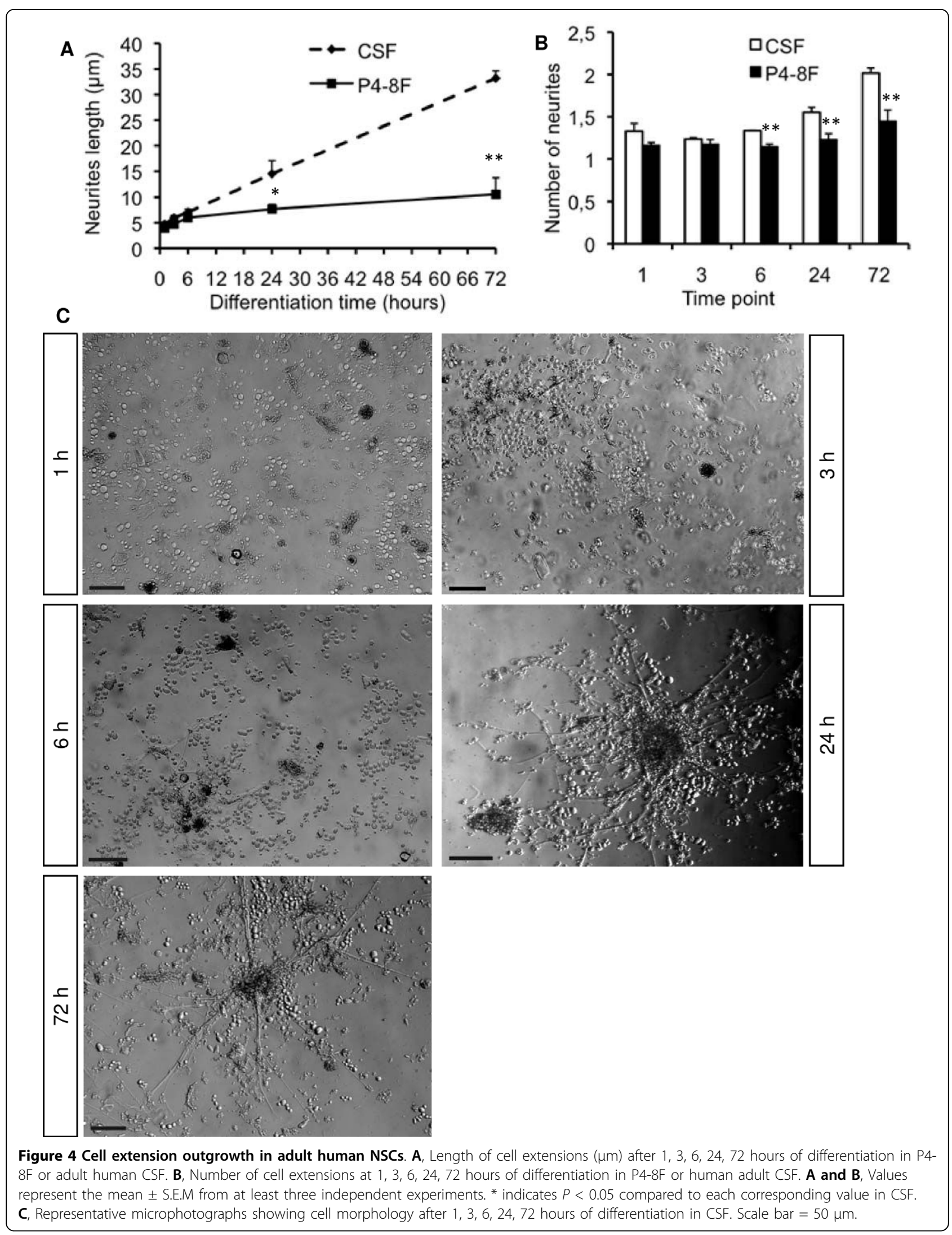




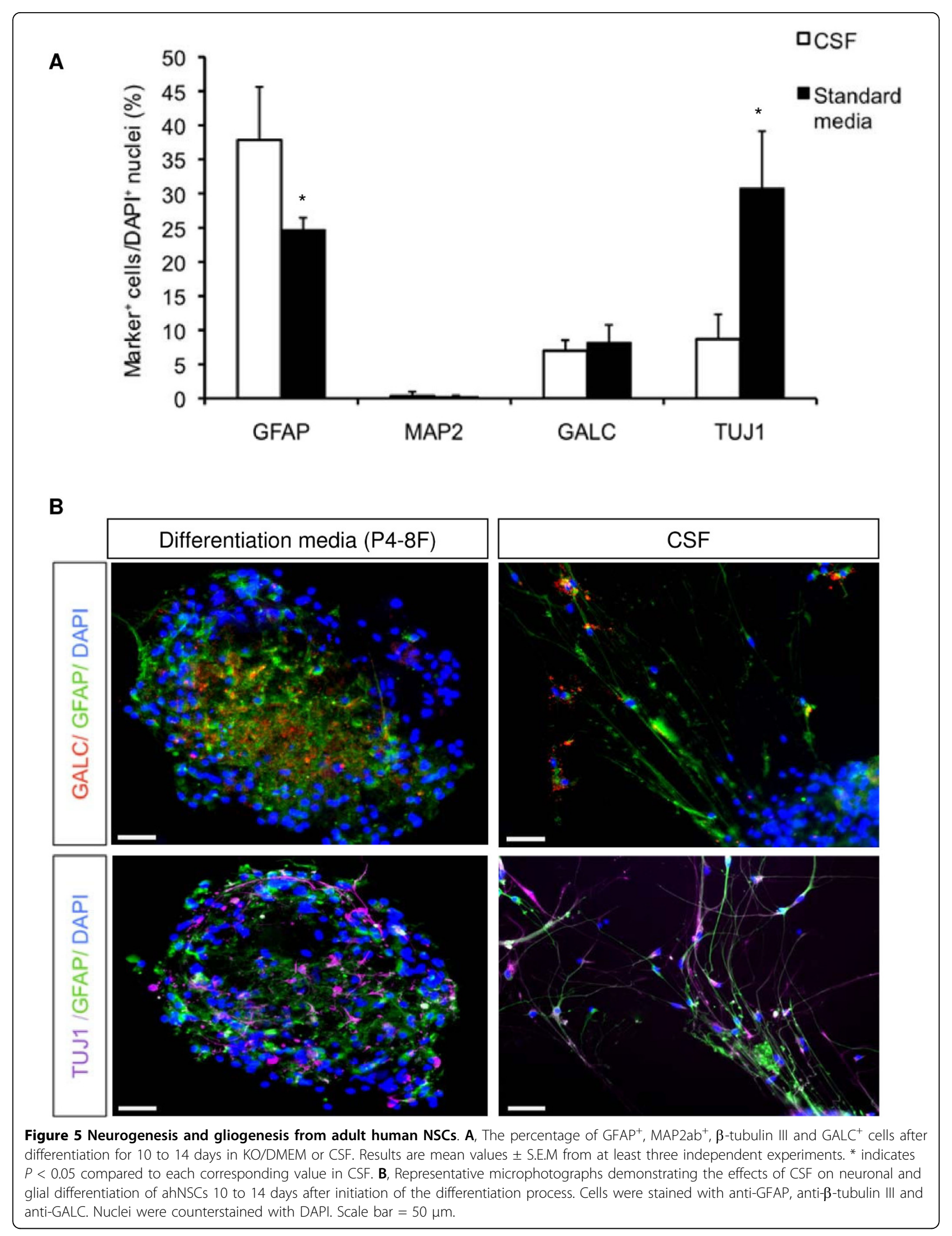




\section{Discussion}

There is growing evidence that CSF plays an important role in physiological as well as pathophysiological processes of the brain including adult neurogenesis [28-30]. In a very recent study of our group, we found adult human leptomeningeal CSF being a promotor of survival, differentiation and astrogliogenesis of fetal NSCs from rat [31]. The influence of CSF on adult NSCs remains however still enigmatic. In this study we therefore used human adult NSCs as an in vitro model to study the effects of adult leptomeningeal CSF on NSC behaviour including survival, self renewal and differentiation. The central finding of our study is that in vitro, adult CSF promotes survival and differentiation of ahNSCs, but drives the differentiation process towards astrogliogenesis. In accordance with these findings, the loss of stem cell potential is accelerated when cultured in adult CSF. These findings suggest that adult CSF contains key factors involved in the control of cellular proliferation and differentiation processes. This assumption is supported by in vivo findings, demonstrating that adult NSCs of the subventricular zone have transitory contact with the ventricular brain cavity and many of them still posses one microcilia which extends into the CSF [32-35]. In addition, it is known from previous studies [21-23] that embryonic CSF has a trophic influence on survival and differentiation of NSCs. However, the loss of stem cell potential is decelerated, which is contradictory to our findings in adult CSF and may explain the abundance of post-mitotic cells in adult CNS.

Based on the knowledge of embryonic CSF studies, it has already been postulated that diffusible factors in embryonic CSF regulate the three basic cellular behavioural parameters of neuroephitelial stem cells and that embryonic CSF may play a key role in brain development in vivo [23].

However, how CSF influences neuroectodermal cells during development remains enigmatic, but the components contained in CSF as well as CSF pressure and flow seem to play an important role $[26,36]$. Regarding the components of CSF influencing neuroectodermal cell behaviour, recent investigations concentrated mainly on proteins, "membranous particles" and amino acids but also on growth factors such as FGF2 [21,24,25,36,37]. In avian and human CSF, many proteins with a known influence on cell survival, neural and glial differentiation, proliferation and signal transduction were found (such as transthyretin, serin, retinol binding protein, heparan sulfate, several apolipoproteins, and FGF2) [22,24,25]. Although it has also been demonstrated that the protein composition of embryonic CSF is more complex than that of adult CSF [22], our results indicate that adult CSF has the capacity to influence the behaviour of adult NSCs in the adult brain, too.

CSF as a beneficial environment for cell survival and growth has also been postulated by in vivo studies, investigating for example the behaviour of fetal NSCs after injection in the fourth ventricle of spinal cord lesioned rats with a good survival of grafted cells within the CSF $[38,39]$, as well as in a recent in vitro study of our own group with fetal rat NSCs [31]. In the present study, CSF had a general stimulating effect demonstrated by the faster loss of self-renewing capacity and stronger cell extension outgrowth. Adult hNSCs differentiated predominantly into astrocytes (38\% in CSF, $25 \%$ in standard media) when treated with CSF and to a lower extend into oligodendrocytes and neurons. After differentiation for 7 days, we found $9 \%$ of the cells to be $\beta$-tubulin ${ }^{+}$in CSF. In standard culture media, $31 \%$ of the cells were $\beta$-tubulin $\mathrm{III}^{+}$. Therefore, our data strongly suggest inhibitory effects of CSF on neurogenesis of ahNSCs, but promoting effects on astroliogenesis. Possible factors in CSF influencing differentiation behaviour of NSCs are bone morphogenetic proteins (BMPs): Monoclonal antibodies against BMP7 were for example shown to inhibit CSF induced dendritic outgrowth of neurons. BMP4 was shown to induce neuronal differentiation of NSCs by activating the ERK and inhibiting the GSK3 $\beta$ pathway. Both described effects could be blocked by Noggin, a BMP inhibitor $[40,41]$. These described effects of BMPs, do have an influence on neuronal differentiation only in fetal NSCs from rat. Until recently, it remained elusive whether these BMPs may also play a role in the observed effects of adult human CSF on astroglial differentiation, but we could show that parts of the CSF mediated effects on fetal rat NSCs could be blocked by Noggin[31]. BMPs thus seem to be at least a part of the soluble factors in the CSF influencing stem cell behaviour in fetal rat NSCs. However, in the present work, we could not find any inhibiting effects of Noggin on CSF survival effects on adult human NSCs. This raises the question whether BMPs influence NSC behaviour only during ontogenesis and therefore have no influence on NSCs derived from the adult brain or whether BMPs might differential effects in human and rat cell systems.

It is well accepted that lumbar CSF is different from ventricular CSF because of both passive diffusion processes across the blood-CSF-barrier and suggested active secretion processes during the cranio-caudal circulation [42]. Consistently, all herein described CSF effects can only be attributed to leptomeningeal CSF. Whether ventricular CSF has similar same effects on NSC behaviour remains elusive. The use of CSF out of ventricular drainages is however problematic, as ventricular drainages 
are used in patients with obstructed CSF circulation (for example cerebral aqueduct stenosis) or other reasons of elevated brain pressure with defect blood-brain- and blood-CSF-barrier (for example after major stroke, after intracerebral bleedings or inoperable brain tumours). Furthermore, CSF out of ventricular drainages is often contaminated by blood and altered by inflammatory processes, which is why it cannot be used for the examination of healthy CSF effects.

\section{Conclusions}

Together, our results demonstrate that adult leptomeningeal CSF has a trophic influence on adult human NSCs: survival and differentiation into astroglial cells are promoted. Thus, our data point to a pivotal role of CSF in regulating adult neurogenesis under physiological and presumably also under pathological conditions as suggested previously [28-30]. Future experiments are warranted to determine which compounds within the CSF, besides BMPs, might be responsible for the effects on NPC behaviour. It also needs to be investigated whether there are different CSF compounds influencing the behaviour of NSCs originating from fetal or adult brain. This might give us the opportunity to influence resident NSCs of the SVZ to induce their proliferation as well as to promote their migration to pathologically altered brain regions.

\section{Methods}

\section{Collection of adult human leptomeningeal CSF}

The CSF samples were taken for diagnostic purpose from adult patients in the Neurological Clinic of the Ernst Moritz Arndt University of Greifswald by a lumbar puncture. Scientific use of CSF samples was approved by the local Ethics Committee. All patients gave a written informed consent for the diagnostic procedure. Lumbar puncture was performed by standard protocols. The final diagnosis of all patients was Idiopathic Normal Pressure Hydrocephalus (NPH). CSF was only used if all standard parameters were normal (cell count, glucose-, lactate. and albumin-content, immunoglobulin-quotient). Contamination with blood was excluded. In all patients, tumors and infectious diseases were excluded. Surplus CSF from diagnostic samples of all patients was spun down to remove remaining cells, pooled and analyzed to exclude non-sterility and presence of inflammatory markers. The pooled CSF was normal in all standard parameters; contamination with blood was excluded once again. The exact parameters were as follows: Cell count $<1 / \mu l$, no blood contamination, normal protein of $369 \mathrm{mg} / \mathrm{l}$, normal glucose of 3.6 $\mathrm{mmol} / \mathrm{l}$, normal lactate of $2.0 \mathrm{mmol} / \mathrm{l}$, normal ferritine of $7.2 \mu \mathrm{g} / \mathrm{l}$, normal albumin quotient of $5.0 \times 10^{-3}$, normal immunoglobulin quotients: IgG $2.1 \times 10^{-3}$, IgA
$1.1 \times 10^{-3}, \operatorname{IgM}<0.2 \times 10^{-3}$. Pooled CSF samples were aliquoted and frozen at $-80^{\circ}$ until used.

\section{Isolation and propagation of adult human neural stem cells (ahNSCs)}

Adult human hippocampal tissue was obtained from routine epilepsy surgery procedures (selective amygdalohippocampectomia) following informed consent of the patients. All procedures were in accordance with the Helsinki convention and approved by the ethics committees at the EMA University of Greifswald (III UV 77/ 06) and at Dresden University of Technology (EK47032006). The tissue was stored in ice-cold Hank's balanced salt solution (HBSS) supplemented with 11 $\mathrm{mM}$ glucose and $1 \%$ penicillin/streptomycin. In all patients, tumours and infectious diseases were excluded by means of high-resolution magnetic resonance imaging and screening for inflammatory markers. Additionally, neuropathological tissue examination did not reveal evidence for tumour formation. For expansion of neurospheres, tissue samples were dissociated using trypsin, DNase and mechanical trituration similar as described previously [19]. Several media and supplements were tested like DMEM, DMEM/F12, Neurobasal (all from Gibco), P4-8F (Athena) with and without N2 or B27 supplements (Gibco) and growth factors. Best results concerning especially the amount of primary neurospheres per dissected hippocampal tissue and the early passage propagation was achieved by Knock-Out DMEM medium, supplemented with $10 \%$ KO supplement; $0.5 \mathrm{mM}$ glutamine; $1 \%$ penicillin/streptomycin (all from Gibco) and $20 \mathrm{ng} / \mathrm{ml}$ both EGF and FGF-2 (from Sigma-Aldrich)(KO/DMEM). Therefore this medium was chosen as control expansion medium. Cultures were incubated at $37^{\circ} \mathrm{C}$ in a humidified atmosphere and lowered $\mathrm{O}_{2}$ conditions of $5 \% \mathrm{CO}_{2}, 92 \% \mathrm{~N}_{2}$ and $3 \pm 2 \%$ $\mathrm{O}_{2}$. Fresh medium was added once a week, growth factors twice a week. For BrdU labelling, cells were incubated with $10 \mu \mathrm{m}$ BrdU for $72 \mathrm{~h}$. For immunocytochemistry studies of neurospheres, these were allowed to attach for 2-4 $\mathrm{h}$ before been fixed as described below.

\section{Differentiation conditions}

Cells were differentiated by plating them onto poly-Llysine-coated chamber slides or 6-well-plates in P4-8F (standard differentiation media; from AthenaES, Baltimore, MD, USA, the albumin-content of P4-8F of $250 \mu \mathrm{g} / \mathrm{ml}$ matches the normal albumin content of healthy adult lumbar CSF, the glucose content of P4-8F is in a physiological concentration of $7 \mathrm{mmol} / \mathrm{l}$ ) or in CSF without adding any growth factors. Some of the differentiation experiments were conducted in the presence of $150 \mathrm{ng} / \mathrm{ml}$ recombinant Noggin (R\&D System, Minneapolis, MN). For studying cell survival, proliferation 
and neurite outgrowth cells were allowed to differentiate for up to 72 hours, for investigating cell fate decisions for up to 7 days respectively. Half of the media was changed every third day. For investigating cell morphology, survival rate and marker expression by immunocytochemistry, the cultures were fixed from $0 \mathrm{~h}$ up to $72 \mathrm{~h}$ and 14 days after starting the differentiation process.

\section{Immunostainings}

For immunocytochemistry, cell cultures were fixed in 4\% paraformaldehyde in PBS or with 4\% paraformaldehyde/PBS followed by ice-cold acidic ethanol and $2 \mathrm{~N}$ HCL for BrdU staining. Immuncytochemistry was carried out using standard protocols. Cell nuclei were counter stained with 4,6-diamidino-2-phenylindole (DAPI). To determine the self renewing potential of NPCs, Ki67 expression and BrdU incorporation were used. Ki67 is detected in the nucleus of proliferating cells in all active phases of the cell cycle from the late G1 phase though the M-phase [43,44]. BrdU marks cells within the S-phase of the cell cycle [45]. Antibodies and dilutions were as follows: rabbit anti-glial fibrillary acidic protein (GFAP) polyclonal 1:1000 (Chemicon International, Temecula, CA, USA), mouse anti-microtubuli associated protein (MAP2ab) monoclonal 1:100 (Pharmingen, San Diego, CA, USA), mouse anti-galactocerebroside (GalC) monoclonal 1:500 (Chemicon), rabbit anti- $\beta$-tubulin III (Tuj1) monoclonal 1:1000 (Covance, Emeryville, CA, USA), rabbit anti-Ki67 polyclonal 1:500 (Berlin Chemie AG, Berlin, Germany), mouse anti-BrdU 1:16 (Roche Applied Science, Mannheim, Germany) and secondary antibodies conjugated to Alexa 488 and 594 1:500 (Gibco/Invitrogen, Carlsbad, CA, USA).

For determining the survival rate during expansion and differentiation, dead cells were stained with propidiumiodid (PI) 1:50 (Sigma Aldrich, St. Louis, USA), cell nuclei were counter stained with Hoechst 33342 1:1000 (Sigma Aldrich, St. Louis, USA). Images were captured using inverse fluorescence microscopes (DMIL and DMI4000, Leica; Wetzlar, Germany).

\section{Cell counts, measurements of neurites and statistics}

For quantification of the percentage of cells expressing a given marker, the number of positive cells of at least five representative areas per experiment was determined relative to the total number of DAPI/Hoechst-labelled nuclei, or field of view in $\mathrm{cm}^{2}$ where appropriate. Neurite lengths were measured with a semi-automatic distance measurement computer program (VisRoute ${ }^{\circ}$. In a typical experiment, a total number of 500 to 1,000 cells were counted per marker, and 500 to 1,000 neurites per time point were measured. The mean values of $\geq 3$ experiments for each condition are given together with standard deviations. Statistical comparisons were made by ANOVA with post-hoc $t$-test or Dunnett's $t$-test where appropriate. P-values $<0.05$ were considered as statistically significant.

\section{Acknowledgements}

The authors may thank all patients that gave the consent to use either tissue samples or CSF, the Department of Neurosurgery for tissue preparation, the Department of Anaesthesiology, the "Epilepsy-Centre" of the EMAU for informing the patients. The authors thank the Departments of Surgery and Clinical Chemistry of the EMAU for allowing us to use parts of their equipment. Special thanks to Sigrid Peters for expert technical assistance. JB and MS were supported by the "Department

Neurowissenschaften" of the Ernst-Moritz-Arndt University of Greifswald. JB was supported by a grant of the Konrad Adenauer Stiftung. AH and AS were supported by the Deutsche Forschungsgemeinschaft through the DFGResearch Centre for Regenerative Therapies Dresden (CRTD).

\section{Author details}

'Department of Neurology, Ernst Moritz Arndt University of Greifswald, 17475 Greifswald, Germany. ${ }^{2}$ Department of Neurosurgery, Ernst Moritz Arndt University of Greifswald, 17475 Greifswald, Germany. ${ }^{3}$ Department of Neurology and Centre for Regenerative Therapies Dresden (CRTD), Dresden University of Technology, 01307 Dresden, Germany. ${ }^{4}$ Department of Neurosurgery, Dresden University of Technology, 01307 Dresden, Germany.

\section{Authors' contributions}

$\mathrm{JB}$ carried out the experiments and drafted the manuscript. MK and $\mathrm{AH}$ participated in part of the experiments. AH helped optimizing the culture conditions. AD provided the CSF samples and supervised the quality control in the CSF laboratory and contributed to the initial study design. HS and MK performed the surgical procedures and provided the tissue samples. UR selected the appropriate patients for the surgical procedures. MS planned the experiments and performed the design and coordination of the study. $J B, M S$ and AS performed the discussion of the study. MS and AS finalized the manuscript. All authors read and approved the final manuscript.

\section{Competing interests}

The authors declare that they have no competing interests.

Received: 9 July 2009 Accepted: 8 April 2010 Published: 8 April 2010

\section{References}

1. Sievertzon M, Wirta V, Mercer A, Meletis K, Erlandsson R, Wikstrom L, Frisen J, Lundeberg J: Transcriptome analysis in primary neural stem cells using a tag cDNA amplification method. BMC neuroscience 2005, 6(1):28.

2. Gage FH: Mammalian neural stem cells. Science (New York, NY) 2000 287(5457):1433-1438.

3. McKay R: Stem cells in the central nervous system. Science (New York, NY) 1997, 276(5309):66-71.

4. Svendsen CN, Caldwell MA, Ostenfeld T: Human neural stem cells: isolation, expansion and transplantation. Brain pathology (Zurich, Switzerland) 1999, 9(3):499-513.

5. Bain G, Kitchens D, Yao M, Huettner JE, Gottlieb DI: Embryonic stem cells express neuronal properties in vitro. Developmental biology 1995, 168(2):342-357.

6. Kawasaki H, Mizuseki K, Nishikawa S, Kaneko S, Kuwana Y, Nakanishi S, Nishikawa SI, Sasai Y: Induction of midbrain dopaminergic neurons from ES cells by stromal cell-derived inducing activity. Neuron 2000, 28(1):31-40.

7. Kawasaki H, Suemori H, Mizuseki K, Watanabe K, Urano F, Ichinose H, Haruta M, Takahashi M, Yoshikawa K, Nishikawa S, et al: Generation of dopaminergic neurons and pigmented epithelia from primate ES cells by stromal cell-derived inducing activity. Proceedings of the National Academy of Sciences of the United States of America 2002, 99(3):1580-1585.

8. Lee SH, Lumelsky N, Studer L, Auerbach JM, McKay RD: Efficient generation of midbrain and hindbrain neurons from mouse embryonic stem cells. Nature biotechnology 2000, 18(6):675-679. 
9. Johansson CB, Momma S, Clarke DL, Risling M, Lendahl U, Frisen J: Identification of a neural stem cell in the adult mammalian central nervous system. Cell 1999, 96(1):25-34.

10. Magavi SS, Leavitt BR, Macklis JD: Induction of neurogenesis in the neocortex of adult mice. Nature 2000, 405(6789):951-955.

11. Reynolds BA, Weiss S: Generation of neurons and astrocytes from isolated cells of the adult mammalian central nervous system. Science (New York, NY) 1992, 255(5052):1707-1710.

12. Rietze RL, Valcanis $H$, Brooker GF, Thomas T, Voss AK, Bartlett PF: Purification of a pluripotent neural stem cell from the adult mouse brain. Nature 2001, 412(6848):736-739.

13. Shihabuddin LS, Horner PJ, Ray J, Gage FH: Adult spinal cord stem cells generate neurons after transplantation in the adult dentate gyrus. J Neurosci 2000, 20(23):8727-8735.

14. Hermann A, Suess C, Fauser M, Kanzler S, Witt M, Fabel K, Schwarz J, Hoglinger GU, Storch A: Rostro-caudal gradual loss of cellular diversity within the periventricular regions of the ventricular system. Stem cells (Dayton, Ohio) 2009, 27(4):928-941.

15. Storch A, Sabolek M, Milosevic J, Schwarz SC, Schwarz J: Midbrain-derived neural stem cells: from basic science to therapeutic approaches. Cell and tissue research 2004, 318(1):15-22.

16. Pagano SF, Impagnatiello F, Girelli M, Cova L, Grioni E, Onofri M, Cavallaro M, Etteri S, Vitello F, Giombini S, et al: Isolation and characterization of neural stem cells from the adult human olfactory bulb. Stem cells (Dayton, Ohio) 2000, 18(4):295-300.

17. Palmer TD, Schwartz PH, Taupin P, Kaspar B, Stein SA, Gage FH: Cell culture. Progenitor cells from human brain after death. Nature 2001, 411(6833):42-43

18. Roy NS, Wang S, Jiang L, Kang J, Benraiss A, Harrison-Restelli C, Fraser RA, Couldwell WT, Kawaguchi A, Okano $H$, et al: In vitro neurogenesis by progenitor cells isolated from the adult human hippocampus. Nature medicine 2000, 6(3):271-277.

19. Hermann A, Maisel M, Liebau S, Gerlach M, Kleger A, Schwarz J, Kim KS, Antoniadis $G$, Lerche $H$, Storch A: Mesodermal cell types induce neurogenesis from adult human hippocampal progenitor cells. Journal of neurochemistry 2006, 98(2):629-640.

20. Maisel M, Herr A, Milosevic J, Hermann A, Habisch HJ, Schwarz S, Kirsch M, Antoniadis G, Brenner R, Hallmeyer-Elgner $S$, et al: Transcription profiling of adult and fetal human neuroprogenitors identifies divergent paths to maintain the neuroprogenitor cell state. Stem cells (Dayton, Ohio) 2007, 25(5):1231-1240.

21. Bachy I, Kozyraki R, Wassef M: The particles of the embryonic cerebrospinal fluid: how could they influence brain development?. Brain research bulletin 2008, 75(2-4):289-294.

22. Gato A, Martin P, Alonso MI, Martin C, Pulgar MA, Moro JA: Analysis of cerebro-spinal fluid protein composition in early developmental stages in chick embryos. J Exp Zoolog A Comp Exp Biol 2004, 301(4):280-289.

23. Gato A, Moro JA, Alonso MI, Bueno D, De La Mano A, Martin C: Embryonic cerebrospinal fluid regulates neuroepithelial survival, proliferation, and neurogenesis in chick embryos. Anat Rec A Discov Mol Cell Evol Biol 2005, 284(1):475-484.

24. Parada C, Gato A, Bueno D: Mammalian embryonic cerebrospinal fluid proteome has greater apolipoprotein and enzyme pattern complexity than the avian proteome. Journal of proteome research 2005, 4(6):2420-2428.

25. Martin C, Bueno D, Alonso Ml, Moro JA, Callejo S, Parada C, Martin P, Carnicero E, Gato A: FGF2 plays a key role in embryonic cerebrospinal fluid trophic properties over chick embryo neuroepithelial stem cells. Developmental biology 2006, 297(2):402-416.

26. Johanson CE, Duncan JA, Klinge PM, Brinker T, Stopa EG, Silverberg GD: Multiplicity of cerebrospinal fluid functions: New challenges in health and disease. Cerebrospinal fluid research 2008, 5:10.

27. Mashayekhi F, Draper CE, Bannister CM, Pourghasem M, Owen-Lynch PJ, Miyan JA: Deficient cortical development in the hydrocephalic Texas $(\mathrm{H}-$ Tx) rat: a role for CSF. Brain 2002, 125(Pt 8):1859-1874

28. Alcazar A, Regidor I, Masjuan J, Salinas M, Alvarez-Cermeno JC: Induction of apoptosis by cerebrospinal fluid from patients with primary-progressive multiple sclerosis in cultured neurons. Neuroscience letters 1998 255(2):75-78.
29. Colombo JA, Napp Ml: Cerebrospinal fluid from L-dopa-treated Parkinson's disease patients is dystrophic for various neural cell types ex vivo: effects of astroglia. Experimental neurology 1998, 154(2):452-463.

30. Redzic ZB, Preston JE, Duncan JA, Chodobski A, Szmydynger-Chodobska J: The choroid plexus-cerebrospinal fluid system: from development to aging. Current topics in developmental biology 2005, 71:1-52.

31. Buddensiek J, Dressel A, Kowalski M, Storch A, Sabolek M: Adult cerebrospinal fluid inhibits neurogenesis but facilitates gliogenesis from fetal rat neural stem cells. Journal of neuroscience research 2009, 87(14):3054-3066.

32. Sawamoto K, Wichterle H, Gonzalez-Perez O, Cholfin JA, Yamada M, Spassky N, Murcia NS, Garcia-Verdugo JM, Marin O, Rubenstein JL, et al: New neurons follow the flow of cerebrospinal fluid in the adult brain. Science (New York, NY) 2006, 311(5761):629-632.

33. Alvarez-Buylla A, Garcia-Verdugo JM: Neurogenesis in adult subventricular zone. J Neurosci 2002, 22(3):629-634.

34. Tramontin AD, Garcia-Verdugo JM, Lim DA, Alvarez-Buylla A: Postnatal development of radial glia and the ventricular zone (VZ): a continuum of the neural stem cell compartment. Cereb Cortex 2003, 13(6):580-587.

35. Vigh B, Manzano e Silva MJ, Frank CL, Vincze C, Czirok SJ, Szabo A, Lukats A, Szel A: The system of cerebrospinal fluid-contacting neurons. Its supposed role in the nonsynaptic signal transmission of the brain. Histology and histopathology 2004, 19(2):607-628.

36. Huttner HB, Janich P, Kohrmann M, Jaszai J, Siebzehnrubl F, Blumcke I, Suttorp M, Gahr M, Kuhnt D, Nimsky C, et al: The stem cell marker prominin-1/CD133 on membrane particles in human cerebrospinal fluid offers novel approaches for studying central nervous system disease. Stem cells (Dayton, Ohio) 2008, 26(3):698-705.

37. Nordin C, Gupta RC, Sjodin I: Cerebrospinal fluid amino acids in pathological gamblers and healthy controls. Neuropsychobiology 2007, 56(2-3):152-158.

38. Bai H, Suzuki Y, Noda T, Wu S, Kataoka K, Kitada M, Ohta M, Chou H, Ide C: Dissemination and proliferation of neural stem cells on the spinal cord by injection into the fourth ventricle of the rat: a method for cell transplantation. Journal of neuroscience methods 2003, 124(2):181-187.

39. Wu S, Suzuki $Y$, Kitada M, Kataoka K, Kitaura M, Chou H, Nishimura Y, Ide C: New method for transplantation of neurosphere cells into injured spinal cord through cerebrospinal fluid in rat. Neuroscience letters 2002 318(2):81-84.

40. Dattatreyamurty B, Roux E, Horbinski C, Kaplan PL, Robak LA, Beck HN, Lein P, Higgins D, Chandrasekaran V: Cerebrospinal fluid contains biologically active bone morphogenetic protein-7. Experimental neurology 2001, 172(2):273-281.

41. Moon BS, Yoon JY, Kim MY, Lee SH, Choi T, Choi KY: Bone morphogenetic protein 4 stimulates neuronal differentiation of neuronal stem cells through the ERK pathway. Experimental \& molecular medicine 2009, 41(2):116-125.

42. Miyan JA, Zendah M, Mashayekhi F, Owen-Lynch PJ: Cerebrospinal fluid supports viability and proliferation of cortical cells in vitro, mirroring in vivo development. Cerebrospinal fluid research 2006, 3:2.

43. Gerdes J, Lemke H, Baisch H, Wacker HH, Schwab U, Stein H: Cell cycle analysis of a cell proliferation-associated human nuclear antigen defined by the monoclonal antibody Ki-67. J Immunol 1984, 133(4):1710-1715.

44. Gerdes J, Schwab U, Lemke H, Stein H: Production of a mouse monoclonal antibody reactive with a human nuclear antigen associated with cell proliferation. International journal of cancer 1983, 31(1):13-20.

45. Eisch AJ, Mandyam CD: Adult neurogenesis: can analysis of cell cycle proteins move us "Beyond BrdU"? Current pharmaceutical biotechnology 2007, 8(3):147-165.

doi:10.1186/1471-2202-11-48

Cite this article as: Buddensiek et al:: Cerebrospinal fluid promotes survival and astroglial differentiation of adult human neural progenitor cells but inhibits proliferation and neuronal differentiation. BMC Neuroscience 2010 11:48. 